XIV Российская национальная конференция по сейсмостойкому строительству и сейсмическому районированию (с международным участием). Сборник материалов

УДК 534.1

DOI 10.37153/2687-0045-2021-14-133-134

\title{
ПОСТРОЕНИЕ СПЕЦИАЛЬНОЙ МАТРИЦЫ ДЕМПФИРОВАНИЯ ДЛЯ МЕТОДА ПРЯМОГО ПОШАГОВОГО ИНТЕГРИРОВАНИЯ
}

Турилов В.В., АО «Атомэнергопроект», кандидат технических наук, с.н.с., начальник лаборатории. Нижний Новгород, Российская Федерация

Уткин И.А., АО «Атомэнергопроект», ведущий инженер. Нижний Новгород, Российская Федерация

\begin{abstract}
Аннотация: Рассматривается методика построения специальной матрицы демпфирования для метода прямого пошагового интегрирования уравнений движения деформируемого твердого тела, эквивалентной матрице демпфирования, формируемой в неклассическом методе модальной суперпозиции.

Ключевые слова: задачи взаимодействия зданий и сооружений с грунтовым основанием, метод прямого пошагового интегрирования уравнений движения, формирование специальной матрицы демпфирования

\section{DEVELOPMENT OF A SPECIAL DAMPING MATRIX FOR THE DIRECT STEP-BY- STEP INTEGRATION METHOD}

Turilov V.V., JSC Atomenergoproekt, Head of Dynamic Analysis Laboratory, PhD.

Nizhny Novgorod, Russian Federation

Utkin I.A., JSC Atomenergoproekt, Leading Engineer. Nizhny Novgorod, Russian Federation

Abstract: A technique for developing a special damping matrix for the direct step-by-step integration method of the equations of motion of a deformable solid body is considered. The generated matrix is equivalent to a damping matrix formed by the non-classical modal superposition method

Keywords: Soil-structure interaction (SSI), direct step-by-step integration method, development of a special damping matrix

В статье [1] был представлен неклассический метод модальной суперпозиции (HMMC), хорошо зарекомендовавший себя при решении задач взаимодействия зданий и сооружений АЭС с грунтовым основанием. Существо данного метода заключается в том, что в пространстве обобщенных (модальных) координат система уравнений движения деформируемого твердого тела не распадается на совокупность независимых уравнений, в отличие от классического метода модальной суперпозиции, а решается как связанная система с применением методов пошагового интегрирования, аналогичных используемым при прямом интегрировании уравнений движения.

Отметим, что в соответствии с нормативным документом [2] (пункт 3.5.4) применение классического метода модальной суперпозиции для задач взаимодействия зданий и сооружений с грунтовым основанием не вполне корректно по причине обычного превышения композитным модальным демпфированием величины $20 \%$ от критического для форм, в основном связанных с колебаниями объекта на «грунтовых» пружинах. Это превышение обусловлено учетом «волнового» («радиационного») демпфирования в грунтовом основании, моделируемого с помощью вязкого демпфирования и вносящего 
XIV Российская национальная конференция по сейсмостойкому строительству и сейсмическому районированию (с международным участием). Сборник материалов

определяющий вклад в демпфирование по указанным формам колебаний системы сооружение - грунтовое основание. Наличие такого превышения является косвенным свидетельством того, что в модальной матрице демпфирования, сформированной корректным образом с учетом «грунтовых» демпферов, имеются достаточно большие недиагональные члены, которые не позволяют рассматривать данную матрицу как диагональную.

Преимуществом НММС перед методом прямого пошагового интегрирования (МППИ) уравнений движения является то, что при его использовании обеспечивается корректный учет конструкционного демпфирования в элементах строительных конструкций (а также материального демпфирования в грунтовом основании), в отличие от МППИ с матрицей демпфирования Рэлея. Напомним, что матрица демпфирования Рэлея обеспечивает заданные значения затуханий только для двух заранее фиксированных частот, а в интервале между ними имеется «провисание» кривой демпфирования, что обусловливает избыточную консервативность ответов системы по собственным формам из указанного частотного интервала. Следует отметить, что «грунтовые» демпферы, а также возможно имеющиеся в составе сооружения (например, в системе виброизоляции) вязкие демпферы, в обоих методах учитываются корректно.

В монографии [3] была указана возможность построения матрицы демпфирования для МППИ, обеспечивающей заданные затухания по формам колебаний системы. В работе [4] данная методика была воспроизведена для случая диагональной матрицы исходного модального демпфирования и применена для решения задачи о взаимодействии промышленного здания с грунтовым основанием при падении на здание самолета.

В настоящей работе аналогичная методика обобщается на случай недиагональной матрицы модального демпфирования с целью построения специальной матрищьь демпфирования для МППИ, обеспечивающей демпфирование в системе, эквивалентное демпфированию, формируемому в неклассическом методе модальной суперпозиции, реализованном в программном комплексе Simcenter Nastran.

С целью верификации разработанная методика реализована средствами языка программирования DMAP Nastran. На реальной задаче показано практическое совпадение результатов при применении НММС и МППИ со спещиальной матрицей демпфирования.

\section{Список литературы}

1. Турилов В.В., Уткин И.А. Применение метода модальной суперпозиции в неклассической форме для решения задач взаимодействия зданий и сооружений АЭС с грунтовым основанием при сейсмических воздействиях // Сейсмостойкое строительство. Безопасность сооружений. - 2017. - № 2. - С. 30-35.

2. ASCE STANDARD. ASCE 4-16 Seismic Analysis of Safety-Related Nuclear Structures / American Society of Civil Engineers, 2017.

3. Бирбраер А.Н., Шульман С.Г. Прочность и надежность конструкций АЭС при особых динамических воздействиях. - М.: Энергоатомиздат, 1989.

4. Коротков В.А., Иванов А.П., Наумкин А.В. Учет модального демпфирования вместо демпфирования по Рэлею в расчетах поэтажных спектров ответа в строительных конструкциях АЭС при падении самолета // SIMULIA Community Conference, 2014. 